\title{
University-Wide Extension Project: Its Impact on Holistic Wellness of Third Agers and Contribution to Development Goals
}

\author{
Manuel E. Caingcoy \\ Bukidnon State University, Philippines \\ *Corresponding author E-mail: caingcoymanuel@gmail.com ORCID ID: 0000-0002-3862-1561
}

\begin{abstract}
Manuscript received 10 Dec 2020; revised 15 Dec. 2020; accepted 10 Jan 2021. Date of publication 15 Jan 2021
Abstract

Holistic wellness is vital to sustaining sound mind and healthy body of third-agers. These individuals are considered vulnerable. Previous surveys indicated limited wellness activities among third agers. With this, an extension project was designed and implemented to address this concern. This paper evaluated the impact of the project on the holistic wellness of third-agers and determined its contribution to national and international goals. The result chain framework was used to identify the impact. It gathered data through survey tools and interviews supported by annual reports. Data were analyzed using descriptive and inferential statistics. The results revealed that the university-wide extension project was successful in implementing activities and producing desired outputs. Its outcomes are evidenced in the attainment of its vision, mission, and objectives. As found, the project had a very high impact on the holistic wellness of third agers in each dimension and as a whole. This means that the third-agers have balanced well-being. This paper also highlights the contributions of the project in the Philippine Development Plan 2017-2022, ambisyon 2040, and sustainable development goals. In the end, relevant recommendations are specifically articulated for future actions.
\end{abstract}

Keywords: Results chain; activities; outputs; outcomes; impact; development; holistic wellness

\section{Introduction}

This Holistic wellness is vital to the lives of the third-agers, especially in sustaining their sound mind and healthy body. This may improve their life expectancy and quality of life. It is multidimensional well-being that includes the social, occupational, emotional, spiritual, intellectual, and physical aspects of the person. These dimensions are interrelated. This means that the condition in one may influence the condition of the others. Thus, holistic wellness goes beyond the physical well-being of third-agers. The interconnectedness among these dimensions signifies the importance of evaluating third agers holistically [1]. In 2015, the population of older adults (60 years old and above) was approximately 7.6 million (7.5\% of the total population). In 2030, this will rise to 14.3 million (11\% of the population). It has been noted that older adults are vulnerable because they are becoming physically fragile and have limited income [2]. This sector needs to be given attention by the government and institutions like universities. In this reality, the graduate faculty, graduate, and undergraduate students of this university were involved in taking actions by conducting studies and activities that were responsive to the needs of this sector. This was to assess, monitor, and document empirical evidence in different topics centered on third-agers in the province. The results were made bases on the crafting of relevant extension programs or projects. The faculty and students from the Social Science Department, College of Arts and Sciences, had conducted studies on the needs of the retirees of Bukidnon [3] and the reasons why senior citizens smoke [4].

Moreover, graduate and undergraduate students of the College Education had also investigated the wellness activities of older adults in Don Carlos Bukidnon [5] and in Kitaotao, Bukidnon [6] perceptions and feelings for senior citizens about being old[7], perceptions of high school students toward senior citizens [8], perceptions of senior citizens toward technology [9], senior citizens health and well-being [10], concerns of senior citizens in Valencia City, Bukidnon [11], and perceptions of first-year students of Bukidnon State University toward older adults [12]. In 2014 and 2015, two studies were conducted on personal views on the retirement of Bukidnon State University Employees [13] and the wellness activities of the older adults in Bukidnon, including the scope and challenges [14]. Lastly, a study through a face-to-face interview was conducted with 20 individuals in Barangay Kalasungay, Malaybalay City, among aged 60 and above. This was to describe how senior citizens (third agers) perceived quality of life. This study generated numerous themes such as health, family and social relations, financial circumstances, social activities, religious beliefs and spirituality, pension, health services, discounts, financial assistance, self-acceptance, positive outlook, productivity, autonomy, sensitivity, and fearlessness [15]. 
The mixed methods research identified the wellness activities of older adults in Don Carlos, Bukidnon. This involved the presidents of senior citizens' association of every barangay. It reported barriers to conduct wellness activities: the lack of time, interest, funding, knowledge, and initiatives; diverse religions and cultures; absence of facilities and government support; and their physical disabilities. Social wellness was found the least present. This study recommended that wellness activities should be given more attention and support from the local government units and concerned sectors. The Department of Social Welfare and Development should spearhead the initiations and implementation of these activities. Otherwise, the quality of life in this sector remains unattended [5]. Furthermore, a study examined older adults' perceptions to acquire an understanding of factors that influence the perception of their wellness. It revealed that perceptions of wellness in older adults are complex and multidimensional constructs. Good health was found to be related to social connectedness and it is not a goal itself [16]. These results imply that wellness is not about the physical or health-related well-being of older adults.

At this stage in life, this sector is defenseless and susceptible to risks related to wellness and health, especially those who had never been employed or financially stable. Aside from the government, this sector needs much attention from their families and or any interested civil societies that advocate and advance their interests. It was reasonable for the university to take part in taking care of the third-agers in the province by responding to earlier studies and in increasing the population of active and holistically balanced older persons. In one study, it was reported that the Bukidnon third-agers were not yet holistically well. It was found they had limited wellness activities. Most of their activities were related to spiritual and physical dimensions. Yet, their spiritual wellness activities were heavily rooted in culture. The same study revealed that intellectual and emotional wellness activities were scarce. Leadership was the most frequently cited reason for the shortage of these activities. It was indicated that there was an absence of balanced wellness. These studies recommended to design, develop, and implement a university-wide extension program or project that would address the situation and make the third-agers holistically well [3], [17].

The foregoing studies had informed graduate faculty, staff, and students. They acknowledged the need to come up with a multidimensional extension project on wellness for this sector. In 2012, a wellness project was finally developed and implemented by this university in partnership with the Coalition of Service of the Elderly (COSE), Government Retirees Association in Bukidnon Incorporated GRABI), and the Office of the Senior Citizens Affairs (OSCA). Sometime in 2017, this was re-classified as a university-wide project that involved colleges and graduate programs of the College of Education. However, its strategies when it started are the same. Its vision states see holistically healthy third agers around supportive families and communities, while its mission is to promote quality of life for all the participants. The project aimed to increase the older adults' awareness of holistic wellness; engage the elderly in holistic wellness activities; collaboratively plan, implement, and evaluate wellness activities with older adults; and for older adults to influence other older adults to engage in holistic wellness activities. This project was the university's response to the mandates of the Republic Act 9994 and the Republic Act 10645 of the Philippines. This impact evaluation intended to provide empirical evidence on the achievements of the project, and evaluated its impact on the holistic wellness of third-agers. Secondly, it tracked whether the vision, mission, and objectives of the project had been realized. Lastly, it determined the contributions of the project to national and international goals. This impact evaluation determined the implemented activities, outputs, and outcomes of the university-wide extension project; and identified the impact on the holistic wellness of third-agers and its contribution to achieving the national and international goals.

\section{Framework of the Study}

The university-wide wellness project was developed based on the six-dimension wellness model of Hettler [1], [18], [19]. This model is on occupational, social, intellectual, physical, emotional, and spiritual wellness. Occupational wellness is the ability of third-agers to contribute unique skills to personally meaningful and rewarding paid or unpaid work, while social wellness refers to their ability to form and maintain positive personal and community relationships. Intellectual wellness is their commitment to lifelong learning through the continual acquisition of skills and knowledge, while physical wellness is their commitment to self-care through regular participation in physical activity, healthy eating, and appropriate health-care utilization. Emotional wellness refers to third agers' ability to acknowledge personal responsibility for life decisions and their outcomes with emotional stability and positivity, while spiritual wellness refers to acquiring purpose in life and their value system. The latter refers to their ability to rise above and go beyond oneself to find meaning and purpose in life [18], [19]. The foregoing holistic wellness model was not used to evaluate the third-agers. Instead, it was made a foundation or basis of the extension project that conducts activities that promote the holistic wellness of third-agers. This impact evaluation used the result chain framework [20], [27] to analyze the achievements of the program through the implemented activities and determine the immediate outputs and outcomes. It is used further to identify the impact of the program on the holistic wellness of third-agers. It determines the contributions of the project to national and international development goals. It is said that to attain long-term results, the organization passes through a series of steps that include inputs, activities, outputs, outcomes, and impact. These terms are used to describe changes or results at different levels [21].

An organization for economic cooperation [20], [27] defined the elements of the results chain. Inputs are the resources needed to carry out activities in the organization. Typically, they refer to money, staff, time, materials and equipment, transportation costs, and infrastructure needed. Activities are actions taken to transform inputs into outputs. In the case of this extension program, these refer to wellness activities. Outputs are the direct results of a set of activities attained and delivered during the activities. Immediately after each wellness activity, outputs can be observed. These may be in the form of capabilities, abilities, skills, systems, policies, or a good that is created, built or repaired. These may also include a new, innovative, or improved offering to clients. Outcomes are what the organization hopes to achieve from the action taken. They are achieved through planned outputs. The organization may or may not have direct control over their achievements. Lastly, the impact is the long-term effect of activities, policies, or services. It may be an implicit or explicit improvement in economic, social, cultural, institutional, environmental, and technological aspects. It is only detectable after months or years of implementation of the program. It is related to broad national or international goals and aspirations [20], [27]. This has something to do with the achievement and realization of the vision, mission, and goals of the organization, which normally indicate impact. In the context of this evaluation, the assumed impact may be observed in the holistic wellness of third-agers. 


\section{Methodology}

This impact evaluation employed a mixed methods research. It reviewed accomplishment reports, conducted interviews and a survey questionnaire to collect the data. Annual reports were used to determine the activities, outputs, outcomes, and contributions of the project The 29-item questionnaire was used to measure the impact of the project on the holistic wellness of third-agers. This questionnaire was administered to 30 third agers during their monthly meetings. Participants accomplished this questionnaire with the help of enumerators who read each item before the participants gave the ratings using a scale of 5 , where 5 is very true to me and qualified as very high impact, while 1 is not true to me at all, which indicates no impact at all. Interview responses were transcribed and their narratives were extracted and cited in the discussion to support the determined impact. Data from the survey were analysed using descriptive and inferential statistics. The annual reports were analysed using content analysis. Contributions of the project in relation to national and international goals were identified.

\section{Results and Discussion}

\subsection{Inputs}

The university had invested in this project through its graduate faculty, staff, and students by sharing their knowledge, skills, and expertise to third-agers. Aside from these, it also funded (extension fund) the activities. Sponsors and donors have also contributed to the attainment of its goals and objectives. It is recognized that both BukSU and its partners shared their facilities and resources. These inputs made all activities possible [28], [29], [30], [31], [32], [33], [34].

\subsection{Activities}

In the second phase of the result chain, thirty-two activities are illustrated for transparency purposes. The bible study, the celebration of Christmas, and some talks relevant to spiritual wellness constitute the spiritual dimension of the project. In particular, the bible study had several sessions with third-agers. These activities constituted $18.75 \%$ or 6 out of 32 activities conducted. In fact, this has become a regular activity during their monthly session with or without the presence of the project implementers, the BukSU faculty, staff, and students. As regards physical aspects, the program had conducted numerous activities such as the seminar on basic nutrition and healthy living, groovy oldie for a healthy elderly, stay involved or stay alive where there were physical exercises, physical wellness for a healthy lifestyle, and the importance of monitoring blood pressure. Additionally, the recognition and a tribute to third-agers, the clean-up drive, and planting of herbs were also conducted. Physical activities are also integrated into other dimensions, especially in activities like the preparation of the area for square-foot gardening and vermicomposting. These constitute $31.25 \%$ or 10 out of 32 activities since the project was launched. For the social dimension, the project had conducted the following storytelling, the nexus between educational philosophy and social responsibility; age, gender, disability, and sensitization; talks on social wellness; the concert and socialization; access to social media; and a talk on friendship. This comprised $25 \%$ of the total activities conducted. In occupational dimension, a lot of activities have been conducted, namely balloon art and financial literacy; square-foot gardening and vermicomposting; zero waste management; math aesthetics; basic accounting and bookkeeping; creativity, and pot gardening; and dish gardening. Like the spiritual dimension, occupational activities constitute $18.75 \%$ of the holistic wellness activities. On intellectual dimension, the project had conducted the intellectual game show; balloon art and financial literacy; square-foot gardening and vermicomposting; zero waste management; math aesthetics; the connection between educational philosophy and social responsibility; managing public-public partnership; basic nutrition and healthy living; age, gender, disability, and sensitization; basic accounting and bookkeeping; training on access to social media; talk on opinions and views on global peace and order; and stimulating cognition. These constitute $40 \%$ or 13 out of 32 activities conducted. Lastly, the emotional activities included were the lectures on age, gender, disability and sensitization; group counselling; a talk on emotional wellness; a seminar on how senior citizens inspire the new generation; and the concert and socials event called dalit. Plainly, $25 \%$ or 8 out of 32 activities were emotional wellness-related. [28], [29], [30], [31], [32], [33], [34]. It can be noticed that some wellness activities are repeated in several dimensions. Theoretically, wellness is multidimensional and its dimensions are interrelated [1].

\subsection{Outputs}

Outputs are the direct results of the activities conducted. Immediately after each wellness activity. These may be in the forms of capabilities, abilities, skills, systems, policies, or a good that is created, built or repaired. These may also include a new, innovative, or improved offering to clients. Evidence shows that the inputs and activities implemented resulted in the acquirements of skills, competencies, knowledge across dimensions of holistic wellness [28], [29], [30], [31], [32], [33], [34].

\subsection{Outcomes}

The outcomes are what the organization hopes to achieve from the action taken in this case, the Bukidnon State University. These outcomes are achieved through planned outputs. The organization may or may not have direct control over their achievements [20]. For this reason, this impact evaluation extends up to looking into whether the vision, mission, and objectives of the project are attained and if so, then this indicates the program outcomes. Each component of the strategies (VMOs) has corresponding remarks that justify how each of them was realized. The evaluation results suggest that the program was successfully implemented. The outcomes are concrete evidence of its success. The project vision reads "see holistically healthy third agers around the supportive families and communities." BukSU, as a community of learners and volunteers, took part in taking care of older adults, and it has been supportive of both research and extension. The project's mission was to promote quality of life for all participants. Every activity that had been conducted with participants has promoted quality life to all third-agers. The first objective was to increase older adults' awareness. This was attained since every activity, seminar, lecture, or talk, on holistic wellness inculcated in every third ager the importance of holistic or balanced wellness. The second objective was to engage the elderly in holistic wellness. Again, this was attained. Each activity allowed every third ager to engage in holistic wellness. The third objective highlights collaborative planning, implementation, and evaluation. This project was a product of constant and strong collaboration between the implementers and partners. It would be impossible to ensure an impact on every third-ager 
without a sustainable partnership. Lastly, its fourth objective reads that for older adults to influence others. The group of third agers has become bigger and bigger [28], [29], [30], [31], [32], [33], [34].

\subsection{Impact}

The extension project has impacted third-agers' holistic wellness (see Tables 1-8). Narratives from the interviews and documented testimonies are cited to support the quantitative impact. Table 1 shows the spiritual wellness of third-agers. The frequency of reading the bible got the lowest mean with a description, true to me. Four items and the overall mean are described very true to me. Generally, these results indicate that all spiritual activities, mostly the bible studies and the celebration of Christmas, had a very high impact on their spiritual wellness. These results imply that the activities have contributed to the spiritual well-being of third-agers. Now, they have a better sense of purpose in life and a strong value system. They can rise above and go beyond themselves to find meaning and purpose in life. From the interview, these narratives extracted: the program helped me spiritually, especially the bible study (P3); BukSU has helped a lot in the spiritual aspect (P5); I am also active in my basic ecclesial community, we meet, share and reflect the word from the bible weekly. We share what we learned from the bible and faith in God $(\mathrm{P} 4)$. These results are consistent with earlier studies that reported that most of the activities related to wellness were spiritual, including praying $(86.36 \%)$, attending mass or worship service and ecclesiastical session $(81.81 \%)$, listening to the gospel/religious music $(50.0 \%)$, devotionals $(45.45 \%)$, being visited by a priest/pastor $(27.27 \%)$, and attending bible study was seldom (36.36\%) done by the participants [3]. As described, spiritual wellness is one's worldview that gives unity and goals to thoughts and actions, as well as the process of seeking meaning, purpose in existence, and understanding of one's place in the universe. Spiritual wellness also included the appreciation of the depth and expanse of life and of the universe along with the acceptance and recognition of the transcendence of the unknown. Furthermore, spiritual wellness is focused on inner and relational harmony with others and the universe, as well as the search for a universal value system [18], [19], [22].

Table 1. Spiritual Wellness of Third-Agers

\begin{tabular}{|c|c|c|c|}
\hline Indicators & Mean & SD & Qualitative Description \\
\hline $\begin{array}{l}\text { 1. I am now frequently engaged in religious activities than before } \\
\text { (e.g. attending church services/masses/ bible study). }\end{array}$ & 4.29 & 1.01 & Very true to me \\
\hline 2. I am now reading the bible more frequently than before. & 3.96 & 1.14 & True to me \\
\hline $\begin{array}{l}\text { 3. I can now appreciate genuine happiness, not through material things, but } \\
\text { through a strong relationship with God. }\end{array}$ & 4.61 & 69 & Very true to me \\
\hline 4. I grow in my personal relationship with the God/Savior/Supreme Being. & 4.75 & .52 & Very true to me \\
\hline 5. I have found a deeper meaning in my life. & 4.75 & .44 & Very true to me \\
\hline Over-all Mean & 4.47 & .57 & Very true to me \\
\hline
\end{tabular}

Table 2 displays the physical wellness of the third-agers. Practicing the acquired techniques and learning activities for their physical fitness turned to have the lowest response from participants, which is described as true to me. No wonder this would be a challenge among older persons because many of them are physically fragile. On the other hand, informing them of the benefits of becoming physically active to maintain good health has the highest response from them, which is described as very true to me. This is at the cognitive or intellectual domain. The overall results indicate that the physical activities conducted by the university had a very high impact on the physical wellness of third-agers. This means that they had maintained their commitment to self-care through regular participation in physical activity, healthy eating, and appropriate health-care utilization. The interviewed individuals had these narratives: the physical exercises helped them a lot (P1); BukSU contributed to my improvement by involving us in physical activities, taught me how to care the self and my responsibility (P5); the university has helped me in terms of health (P2). This is partly supported by a study [3] which reported that older persons in the province had availed medical care, exercising activities, listening to speakers on physical wellness talks, and nutrition. In a similar study, a number of barriers or reasons for the lack of physical activities in barangays: physical disability, departed partner, laziness, hesitant to join morning exercise, lack of equipment, lack of resource persons, limited knowledge, weak leadership and too weak to do it [3].

Table 2. Physical Wellness of Third-Agers

\begin{tabular}{|c|c|c|c|}
\hline Indicators & Mean & $\mathrm{SD}$ & Qualitative Description \\
\hline $\begin{array}{l}\text { 1. I constantly practiced the acquired techniques and learned activities that can } \\
\text { make me more physically fit. }\end{array}$ & 4.14 & 1.01 & True to me \\
\hline 2. I am now giving more importance to my health than before. & 4.64 & .73 & Very true to me \\
\hline $\begin{array}{l}\text { 3. I am more informed about the benefits of becoming physically active to } \\
\text { maintain my good health. }\end{array}$ & 4.74 & .59 & Very true to me \\
\hline 4. I learned further on healthy eating habits and practices. & 4.56 & .58 & Very true to me \\
\hline 5. I am now committed to giving more value to my health. & 4.62 & .57 & Very true to me \\
\hline Over-all Mean & 4.48 & .61 & Very true to me \\
\hline
\end{tabular}

Physical wellness encompasses the degree to which one maintains and improves cardiovascular fitness, flexibility, and strength. This dimension stressed the importance of maintaining a healthy diet and attempting to produce bodily balance and harmony through aware- 
ness and monitoring of body feelings, internal states, physical signs, tension patterns, and reactions. It includes seeking appropriate medical care and taking action to prevent and detect illnesses. In sum, Hettler's definition of physical wellness encompasses one's attention to physical self-care, activity level, nutritional needs, and use of medical services [19], [22].

Table 3. Social Wellness of Third-Agers

\begin{tabular}{lccc}
\hline Indicators & Mean & SD & Qualitative Description \\
\hline 1. I am now more positive and open to different invitations for socials. & 4.43 & .96 & Very true to me \\
2. I am now more involved and actively engaged in my senior citizens' organization. & 4.75 & .80 & Very true to me \\
3. I am now more engaged or active in different social gatherings. & 4.43 & .96 & Very true to me \\
4. I am more responsive to a different invitation for socials than before. & 4.43 & .92 & Very true to me \\
5. I can now interact and relate with different people than in the past years. & 4.26 & .90 & Very true to me \\
Over-all Mean & 4.47 & .77 & Very true to me
\end{tabular}

Table 3 presents the results on social wellness. These results revealed that interacting and relating with different people had the lowest mean, while active involvement and engagement in senior citizens' organization had the highest mean. Both items have a description, very true to me. Further, all items including the over-all mean got the response very true to me. This suggests that the social wellness activities conducted had a very high impact on the social wellness of the third-agers. This means further that third agers have a strong ability to form and maintain positive personal and community relationships. One interviewee mentioned that socially the program has greatly helped me personally (P1). In a local study, the following was reported: attending parties (68.18\%), visiting neighbours (68.18\%), visiting friends $(68.18 \%)$, visiting a member of the family $(54.54 \%)$, conversing anyone who crossed their path (54.54\%), and attending a concert $(9.09 \%)$ [3]. A foreign study claims that "participation in inclusive community activities of this type builds friendships and community networks, improving well-being" [23, p. 1]. The social dimension emphasizes individuals in relation to others and to the environment. The relationship includes the extent to which an individual contributes to the common welfare of the community and environment and the level of interdependence with others and nature. Socially well individual is someone who is living in harmony with others working toward mutual respect and cooperation. Social wellness involves the active promotion of a healthy environment and the betterment of the community; effective communication and healthy relationships with others and a balance and integration of self with others, the community, and nature [18], [19], [22].

Table 4. Occupational Wellness of Third Agers

\begin{tabular}{lllll}
\multicolumn{1}{c}{ Indicators } & Mean & SD & Qualitative Description \\
\hline 1. I learned a lot of skills from the wellness program. & 4.37 & 1.04 & Very true to me \\
2. I can use learned skills for livelihood. & 4.11 & 1.17 & True to me \\
3. I am now more active in gardening at our backyard than before. & 4.04 & 1.20 & True to me \\
4. I become more aware of the importance of caring for the surroundings, especially \\
mother nature. & 4.32 & .94 & Very true to me \\
$\quad$ Over-all Mean & 4.24 & .86 & Very true to me \\
\hline
\end{tabular}

Table 4 displays the occupational wellness of agers. As shown, active engagement in gardening has the lowest mean and qualitative description, true to me. However, learning a lot of skills has the highest mean with a qualitative description of very true to me. The former indicates a high impact, while the latter suggests a very high impact. As a whole, the occupational wellness of the third-agers is described very true to me, which indicates that the occupational wellness activities had a very high impact on the occupational wellness of these individuals. This means that those activities have improved their ability to contribute unique skills to personally meaningful and rewarding paid or unpaid work. When third agers were asked if the program has helped them: Yes, it helped especially the gardening (P2); the activity that helped me a lot is on planting because I will no longer buy in the market (P5); I planted vegetables in a recycled pot and we benefited from it and we harvested our planted vegetables (P6); currently, I have lots of vegetables at home because I applied what I learned from the program. Seldom I buy in the market and only those not available in my garden (P4). What this beneficiary referred to is the dish gardening, pot gardening, and square-foot gardening. They were trained on how to plan using a pot. In the study [3], these statistics were reported: participating in church projects (59.09\%), participating in community projects (50.00\%), participating in government projects $(50.00 \%)$, participating in NGO projects $(40.90 \%)$, participating in extension programs (18.18\%), and participating in volunteer programs $(13.63 \%)$. Occupational wellness refers to the level of satisfaction and enrichment gained by one's work and the extent to which one's occupation allows for the expression of one's values. Furthermore, occupational wellness includes the contribution of one's unique skills and talents to the community in rewarding, meaningful ways through paid and unpaid work, as well as the balance between occupational and other commitments [18], [19], [22]. 
Table 5. Intellectual Wellness of Third Agers

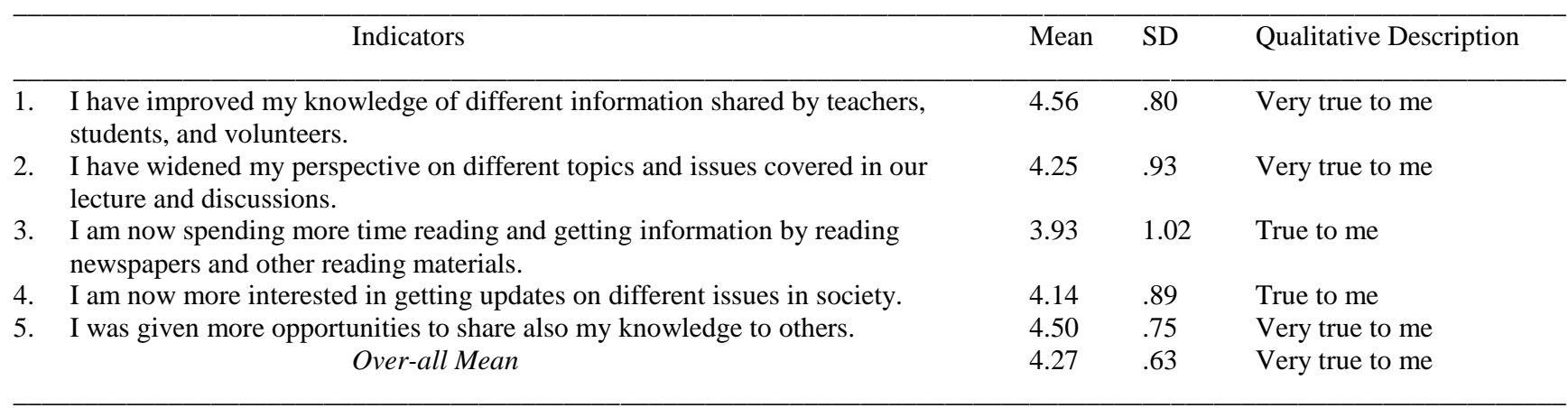

Table 5 illustrates the intellectual wellness of the third-agers. Specifically, spending more time reading and get information by reading newspapers and other reading materials has the lowest response, while the improvement in their knowledge of different information shared by the teachers, students, and volunteers turned to have the highest response. Generally, the intellectual wellness activities conducted had a very high impact on the intellectual wellness of third-agers. This means that those activities had enhanced their commitment to lifelong learning through the continual acquisition of skills and knowledge. In documented testimonies in vernacular, these were written: nakatabang ang proyekto ilabina sa kulang sa kaalam may kalabigitan sa financial; nakatabang kay nadunganan ang among kahibalo; nabuka ang akong pang-isip na dapat magpalano. A study in the locale [3] found limited intellectual activities were reported these are on word puzzle games $(9.09 \%)$ and learning computers $(4.54 \%)$. This wellness has something to do with the degree to which one engages mind in creative and stimulating activities, as well as the use of resources to expand one's knowledge. The definition focuses on the acquisition, development, application, and articulation of critical thinking. Intellectual wellness is one's commitment to lifelong learning and the effort to share knowledge with others. Finally, intellectual wellness focuses on one's skills and abilities that achieve a more satisfying life [18], [19], [22].

Table 6 exhibits the results of emotional wellness. The results indicate that controlling emotion has the lowest response while being calm in the midst of personal problems turned to have the highest response. All indicators indicate that these very true to third agers. Largely, emotional wellness activities had a very high impact on the emotional wellness of third-agers. This would mean that those activities have improved their ability to acknowledge personal responsibility for life decisions and their outcomes with emotional stability and positivity. These narratives support this impact: Emotionally, BukSU's extension helped me personally (P1); because of the bible study, it changed my attitudes and I can control myself (P4). In the needs assessment study, these activities were documented: listening to speakers on how to handle emotions, participating in support groups, group sharing, seminar-workshop on grand parenting, and film-viewing about stress management [3].

Table 6. Emotional Wellness of Third Agers

\begin{tabular}{|c|c|c|c|}
\hline Indicators & Mean & $\mathrm{SD}$ & Qualitative Description \\
\hline 1. I can now control my emotions than before. & 4.48 & .58 & Very true to me \\
\hline 2. I am now more calm than before despite the problems that may come to life. & 4.64 & .56 & Very true to me \\
\hline 3. I am now more aware of others' emotions. & 4.61 & .50 & Very true to me \\
\hline 4. I am more positive in perceiving life than the way I perceived it before. & 4.54 & .51 & Very true to me \\
\hline 5. I can now make big and objective decisions without the influence of my emotion. & 4.56 & .70 & Very true to me \\
\hline Over-all Mean & 4.57 & .46 & Very true to me \\
\hline
\end{tabular}

Emotional wellness is a continual process that incorporates awareness, constructive expression, and management of emotions, as well as a realistic self-assessment and positive approach to life. It also refers to the awareness and acceptance of a wide range of feelings in one's self and others, as well as one's ability to constructively express, manage, and integrate feelings [18]. It was recognized that one's choices are the expression and integration of feelings, cognitions, and behaviors. An emotionally well person is flexible, open to development, able to function autonomously, and is aware of his or her limitations [19].

As a whole, the overall impact of the extension program on the holistic wellness of third agers is shown in Table 7. The results indicate further that all activities of the extension project at six dimensions had a very high impact on the holistic wellness of the beneficiaries. This indicates that the third-agers have balanced wellness. As has been argued that, "A person who experiences optimum wellness also has mental, emotional, social, vocational, and spiritual health, and the opportunity to know about and choose activities that support overall wellness" $[24$, p. 2]. It was also claimed that holistic wellness goes beyond the physical well-being of third-agers. Interconnectedness among these dimensions signifies the importance of evaluating older adults or third-agers holistically [1]. These claims are true except between the spiritual and social wellness in the case of the present study. 
Table 7. Holistic Wellness of Third-Agers

\begin{tabular}{lccll}
\hline Dimensions & Mean & SD & Qualitative Description & Interpretation \\
\hline 1. Spiritual & 4.47 & .57 & Very true to me & Very High Impact \\
2. Physical & 4.48 & .61 & Very true to me & Very High Impact \\
3. Social & 4.47 & .77 & Very true to me & Very High Impact \\
4. Occupational & 4.24 & .86 & Very true to me & Very High Impact \\
5. Intellectual & 4.27 & .63 & Very true to me & Very High Impact \\
6. Emotional & 4.57 & .46 & Very true to me & Very High Impact \\
Over-all & 4.42 & .65 & Very true to me & Very High Impact \\
\hline
\end{tabular}

Table 8. Correlation among Dimensions of Holistic Wellness

\begin{tabular}{|c|c|c|c|c|c|c|c|c|}
\hline \multicolumn{2}{|c|}{ Variables } & \multirow{2}{*}{$\begin{array}{l}1 \\
-\end{array}$} & \multirow{2}{*}{$\begin{array}{l} \\
.527 * *\end{array}$} & \multirow{2}{*}{$\begin{array}{l}3 \\
.362\end{array}$} & \multirow{2}{*}{$\begin{array}{l}4 \\
.596 * *\end{array}$} & \multirow{2}{*}{$\begin{array}{l}5 \\
.549 * *\end{array}$} & \multirow{2}{*}{$\begin{array}{l}6 \\
.474 *\end{array}$} & \multirow{2}{*}{$\begin{array}{l}\text { over-all } \\
.704 * *\end{array}$} \\
\hline 1. & Spiritual & & & & & & & \\
\hline & & & .004 & .058 & .001 & .002 & .011 & .000 \\
\hline \multirow[t]{2}{*}{2.} & Physical & $.527 * *$ & - & $.593 * *$ & $.826 * *$ & $.764 * *$ & $.521 * *$ & $.875 * *$ \\
\hline & & .004 & & .001 & .000 & .000 & .004 & .000 \\
\hline \multirow[t]{2}{*}{3.} & Social & .362 & $.593 * *$ & - & $.568 * *$ & $514 * *$ & $.476^{*}$ & $.740 * *$ \\
\hline & & .058 & .001 & & .002 & .005 & .010 & .000 \\
\hline \multirow[t]{2}{*}{4.} & Occupational & $.596 * *$ & $.826 * *$ & $.568 * *$ & - & $.874 * *$ & $.573 * *$ & $.925 * *$ \\
\hline & & .001 & .000 & .000 & & .001 & .000 & .000 \\
\hline \multirow[t]{2}{*}{5.} & Intellectual & $.549 * *$ & $.764 * *$ & $.514 * *$ & $874 * *$ & - & $.654 * *$ & $.894 * *$ \\
\hline & & .002 & .000 & .005 & .000 & & .000 & .000 \\
\hline \multirow[t]{4}{*}{6.} & Emotional & $.474 *$ & $.521 * *$ & $476^{*}$ & $.573 * *$ & $.654 * *$ & - & $.825 * *$ \\
\hline & & .011 & .004 & .010 & .001 & .000 & & .000 \\
\hline & Over-all & $.704 * *$ & $.785 * *$ & $.740 * *$ & $.925 * *$ & $.894 * *$ & $.825 * *$ & - \\
\hline & & .000 & .000 & .000 & .000 & .000 & .000 & \\
\hline
\end{tabular}

Notes: **Correlation is significant at the 0.01 level (2-taiiled); ${ }^{*}$ Correlation is significant at the 0.05 level(2-tailed)

\subsection{Contributions to Development Goals}

The project had contributed to the Philippine Development Plan (PDP) 2017-2022, particularly on promoting Philippine culture and values, accelerating human capital development, and reducing the vulnerability of individuals and families [25]. It also contributed to the long-term aspiration of the Filipinos in Ambisyon 2040 [2]. These are on making Filipinos secure or feel secured over their lifetime, live long and enjoy a comfortable life upon retirement, a caring society, and strongly rooted Filipinos for volunteerism. Lastly, it contributed also to achieving the Sustainable Development Goals (SGDs) on good and well-being (SD3), reduce inequalities (SDG10), climate action (SGD13), and partnership for goals (SGD17) [26]. On promoting Philippine culture and values, one strategy was to strengthen culture-sensitive governance and development. For this, the government aims to strengthen the protection of the vulnerable sectors of society. On this aim, the extension project contributed to its attainment by giving importance to third agers and by designing and implementing activities that promote holistic wellness. This sector is vulnerable and needs attention and care from the government and any interested institutions like BukSU. The project itself is culture-sensitive in which spiritual wellness did not promote any religion or sect. The third agers joined in the ecumenical bible study every last Saturday of the month [28], [29], [30], [31], [32], [33], [34]. In accelerating human capital development, one strategy was to guarantee care at all life stages. Two activities that can be done in this strategy: provide quality nutrition and health care interventions at all life stages; and improve health-seeking behaviors of the citizens, especially the most vulnerable. One of the activities under the physical dimension of the project wellness was the seminar on basic nutrition and healthy living. By the fact that the project beneficiaries are third-agers, the initiative was responsive to providing health care awareness on what the government provides them for free - the health and wellness related services. The project provided them talks with related measures [28], [29], [30], [31], [32], [33], [34]. Making them aware can change their behaviors toward improving their health status. As a strategy, the government intends to mitigate the risks faced by vulnerable groups. For this, it shall implement a convergence approach to help the poor and vulnerable become self-sufficient and self-reliant. The extension project contributed to the attainment of this goal because it covered the intellectual wellness in which a lot of information was given on how vulnerable they are. The project itself, with its activities and as a whole, is mitigation, especially when the third-agers become holistically well and their wellness becomes balanced. All these efforts are converging with government intentions.

One of the goals of Ambisyon 2040 is that Filipinos are secured or feel secure over their lifetime [2]. The constant attendance and involvement of the third-agers in the different activities of the project is a manifestation that they feel cared for by the university. The project provided third-agers with opportunities and a chance to be cared for by the faculty, students, and staff. It is articulated in Ambisyon 2040 that Filipinos would live long and enjoy a comfortable life upon retirement. Engaging third-agers in this project and its activities had made their lives busy, active, and enjoyable than simply staying at their homes with ordinary routines. Encouraging them to be active physically, intellectually, and socially can make their lives even longer [28], [29], [30], [31], [32], [33], [34]. Ambisyon 2040 hopes for 
Filipinos a caring society [2]. Venues and opportunities for this hope must be provided for interpersonal interaction. With the social wellness activities of the project, it contributed by allowing them to socialize with other older adults. Every activity, they had this opportunity to connect with others. The activities are venues for their interaction. Lastly, the Ambisyon 2040 under the "Matatag" or strongly rooted Filipinos- volunteering was highly encouraged [2]. The project promoted the value and sense of volunteerism among faculty, staff, and students as well as to partners or collaborators. In this, there is a strong sense of community by extending services to this vulnerable sector [28], [29], [30], [31], [32], [33], [34].

One of the Sustainable Development Goals is good health and well-being (SDG3) [26]. The wellness project went beyond promoting the physical well-being of the third-agers. It even provided holistic and multidimensional wellness. It covers the different aspects of third agers' well-being. To reduce inequalities (SGD10) is what the United Nations wishes to achieve [26]. The third agers/senior citizens have been neglected, and usually they were given less attention, provision, and special privileges. Choosing them as beneficiaries of the project, contributed to achieving this goal and eventually narrowed down the inequalities that concerned them. Sustainable Development Goal 13 highlights the need for climate action [26]. Under the intellectual and occupational wellness, the project had given third agers lectures on zero waste management, dish gardening, square-foot gardening, and pot gardening. These are small but vital efforts to mitigate climate change in their own direct environment [31]. Lastly, SGD 17 articulates the need for the partnership for goals [26]. The project, from its conceptualization, during the implementation and up to the evaluation period had a lot of partners and collaborators to attain the vision, mission, and objectives of the project [28], [29], [30], [31], [32], [33], [34].

\section{Conclusion}

This impact evaluation concluded that third-agers become able to contribute unique skills to personally meaningful and rewarding paid or unpaid work, able to form and maintain positive personal and community relationships, and more committed to lifelong learning through the continual acquisition of skills and knowledge. They are more committed to self-care through regular physical activity, healthy eating, and appropriate healthcare utilization. They are able to acknowledge personal responsibility for life decisions and their outcomes with emotional stability and positivity. Lastly, they developed a greater sense of purpose in a life grounded on their strong value system. Additionally, the more they can go beyond themselves to find meaning and purpose in their existence. The impact of the program encompassed the holistic wellness of third-agers since it has significant contributions to national and international development goals. This report recommends: that impact evaluation may be done annually since a few of the third agers find it challenging to recall the activities conducted and they tend to forget how the activities were done by the facilitators; that there would be another study that estimates the contribution of each dimension to the holistic wellness of third-agers using regression analysis. This is to confirm the literature that reported wellness as multidimensional and its dimensions as interrelated and that the improvement in one dimension results in an improvement in another; there is a need to strengthen the monitoring and documentation. There may be an analysis of evaluation of every activity, audios and videos of documented activities; dimensions of holistic wellness need to be equally represented in activities; that the national, regional, and local government units may grant incentives to organizers and implementers of any program and project for the holistic wellness of third agers so that there would be more organizations, institutions and civil societies that advance the interest and welfare of third-agers; that the government may call for different initiatives relevant to the well-being of third agers and encourage strong collaboration among industry, academe, and civil societies to take part in taking care third agers by creating programs and projects that benefit them; and hen third-agers were asked what they could recommend to BukSU that may help them, they mentioned: livelihood for additional income; more physical exercises or dances for fitness; tree planting; bookkeeping; availing more benefits for health maintenance; family relationships; planting vegetables in pots; and encouraging the community to practice planting vegetables in pots.

\section{Acknowledgement}

The author is indebted and is grateful to all the third agers who were involved in the project and in conducting this impact evaluation.

\section{References}

[1] K. A. Strout and E. P. Howard, "The Six Dimension of Wellness and Cognition in Aging Adults", Journal of Holistic Nursing, 30 (3), 195-204, 2012. DOI: $10.1177 / 0898010112440883$ Accessed at http://jhn.sagepub.com

[2] National Economic and Development Authority, “Ambisyon Natin 2040: A Long Term Vision for the Philippines”, Pasig City, Philippines, NEDA 2017.

[3] B. R. Torres, "The Scope and Challenges of the Wellness Activities of the Older Adults", Liceo Journal of Higher Education Research, 82-101, 2017.

[4] A. M. Ravelo, L. D. J. Mendez, G. Dumalahay and J. Agopo, "Reasons why senior citizens in Barangay 9 Gawad Kalinga Smoke", Master's Thesis, Malaybalay City, Bukidnon, Philippines, Bukidnon State University, 2014.

[5] G. U. Paña and V. V. Pagulong, "The Wellness Activities for Older Adults in Don Carlos Bukidnon", Malaybalay City, Bukidnon, Philippines: Bukidnon State University, 2013

[6] H. B. Baring and T. D. L. Clavel, "Wellness Activities for Senior Citizens in Kitaotao, Bukidnon", Master's Thesis, Malaybalay City, Bukidnon, College of Teacher Education, Bukidnon State University, 2013.

[7] L. M. B. Abalo and S. Q. Pacomios, "Perceptions and Feeling for Senior Citizens about being Old", Master's Thesis. Malaybalay City, Bukidnon, Philippines, College of Teacher Education, Bukidnon State University, 2013.

[8] C. C. Ong and A. D. Loson, "Perceptions of High School Students towards Senior Citizens", Master's Thesis. Malaybalay City, Bukidnon, Philippines: College of Teacher Education, Bukidnon State University, 2013.

[9] A. G. D. Parcon and M.M.A. Rivera, "Perceptions of Senior Citizens towards Technology" Master's Thesis, Malaybalay City, Bukidnon, Philippines, College of Teacher Education, Bukidnon State University, 2013. 
[10] D. F. A Neri, R. O. Lumbab and L. D. D. Veloso, “Senior Citizens health and Well-being”, Master's Thesis, Malaybalay City, Bukidnon, Philippines, College of Arts and Sciences, Bukidnon State University, 2013.

[11] I. S. Vilchez and P. J. A. Zuniga, “Concerns of Senior Citizens in Valencia City, Bukidnon”, Master's Thesis. Malaybalay City, Bukidnon, Philippines, College of Education, Bukidnon State University, 2013.

[12] K. M. M. Cordero and I.L. Calforo, "Perceptions of First Year Students of Bukidnon State University towards older adults", Master's Thesis, Malaybalay City, Bikidnon, Philippines, BukSU, 2013.

[13] J. C. D. Carbajal, "Personal views on retirement of Bukidnon State University Employees", Master's Thesis, Malaybakay City, Bukidnon, Philippines, Bukidnon State University, 2015.

[14] B. R. Torres, “The wellness activities of the older adults in Bukidnon: scope and challenges”. Studies About the Elderly or Third Agers Conducted by the Students, Faculty, and Staff of Bukidnon State University, Malaybalay City, Bukidnon, Philippines, Bukidnon State University, 2015.

[15] D. M. Gabales and M. L. Garote, "Quality of life of the Senior Citizens in Barangay Kalasungay", Undergrad Thesis, Malaybalay City, Bukidnon, Philippines: Bukidnon State University, 2013.

[16] J. A. Foottit, "Wellness in Older Adults", A Dissertation, Queensland, School of Nursing and Institute of Health and Biomedical Innovation, Queensland University, 2009.

[17] B. R. Torres, "The needs of the retirees of Bukidnon", Malaybalay City, Bukidnon, Philippines: Bukidnon State University, 2009.

[18] B. Hettler, "The six dimension of wellness", 1976. Accessed from http://www.hettler.com/sixdimen.htm

[19] B. Hettler, "Wellness promotion on a university campus: Family and community health", Journal of Health Promotion and Maintenance, 3, 77-95, 1980.

[20] Organization for Economic Cooperation and Development. "Glossary of Key Terms in Evaluation and Results-Based Management", OECD, 2002.

[21] T. Winderl, "The results chain: a beginner's guide", 2016, Accessed from http://winderl.net/resultschain/

[22] R. Russ, "Wellness Activities of Rural Older Adults in the Great Plains", Online Journal of Rural Research and Policy, 7(1), 1-14, 2012. Accessed from https://doi.org/10.4148/ojrrp.v7i1.1626

[23] J. Peterson-Besse, "Advocating for Quality, Inclusive Wellness Opportunities in Our Communities", Impact, 29 (1), 1, 34-35, 2016.

[24] L. Anderson and J. Flowers, "From Wellness to Flourishing for People with Intellectual and Developmental Disabilities", Impact, 29 (1), 2-3, 2016.

[25] National Economic and Development Authority, "Philippine Development Plan 2017-2022", Pasig City, Philippines, National Economic and Development Authority, 2017.

[26] United Nations, "Transforming the World: The 2030 Agenda for Sustainable Development", Netherlands, UN, 2016.

[27] D. Kinyuira, "Using Results Chain Framework as a Tool for the Improvement of Performance Evaluation in Firms", Journal of Strategy and Performance Management, 7(1), 28-36, 2019.

[28] Bukidnon State University, "Project Wellness for the Third Agers: Gender, Age and Disability Sensitization", Accomplishment Report, Malaybalay City, Bukidnon, Philippines, BukSU Gender Unit, May 2018.

[29] Bukidnon State University, "Project Wellness for the Third Agers: Lecture and Workshop on Basic Accounting and Bookkeeping for Senior Citizens (Intellectual Wellness)", Acccomplishment Report, Malaybalay City, Bukidnon, Philippines, College of Business, April 2018),

[30] Bukidnon State University, "Project Wellness for the Third Agers, Accomplishment Report, Malaybalay City, Bukidnon, Philippines, BukSU. 2018.

[31] Bukidnon State University, "Project Wellness for the Third Agers: Seminar-Workshop on Environmental Resource Management for the Third Agers", Accomplishment Report, Malaybalay City, Bukidnon, Philippines, College of Arts and Sciences, and College of Education, 2018.

[32] Bukidnon State University, "Project Wellness for the Third Agers: Basic Nutrition and Healthy Living for the Elderly", Accomplishment Report, Malaybalay City, Bukidnon, Philippines: BukSUCollege of Social Development and Technology, 2018.

[33] Bukidnon State University, "Project Wellness for the Third Agers: Bible Study", Accomplishment Report, Malaybalay City, Bukidnon, Philippines, Social Science Department, College of Arts and Sciences, BukSU, May 2018.

[34] Bukidnon State University, "Evaluation of Project Wellness for the Third agers", Malaybalay City, Bukidon, Philippines, Extension Unit, n.d. 